\title{
Heuristic Thinking and Teaching Practice of Digital Circuit Online Course
}

\author{
Lei Zhao \\ Electronic Experimental Center, Chengdu University of Information Technology, Chengdu, China \\ Email: zhaolei@cuit.edu.cn
}

How to cite this paper: Zhao, L. (2020). Heuristic Thinking and Teaching Practice of Digital Circuit Online Course. Open Journal of Social Sciences, 8, 118-127. https://doi.org/10.4236/jss.2020.88010

Received: July 10, 2020

Accepted: August 16, 2020

Published: August 19, 2020

Copyright $\odot 2020$ by author(s) and Scientific Research Publishing Inc. This work is licensed under the Creative Commons Attribution International License (CC BY 4.0).

http://creativecommons.org/licenses/by/4.0/

\section{(c) (i) Open Access}

\begin{abstract}
Based on the design and experience of "digital circuit" online course, this paper analyzes the existing problems in teaching and rethinks how to impart knowledge and skills more effectively in the network environment. Apply a heuristic approach to digital Circuits and Systems Design. In practice, the complex design problems are solved step by step through the idea of "question heuristic consideration-solution" by adopting four steps of "raising questions", "enlightening thinking", "bifurcating solutions" and "comparative analysis". The teaching intention, teaching design and teaching behavior should be comprehensively reflected and improved, to improve teaching behavior and improve teaching ability. The teaching practice shows that heuristic teaching has achieved good teaching effect and is worthy of further promotion.
\end{abstract}

\section{Keywords}

Digital Circuit Course, Heuristic Teaching, Teaching Practice, Multisim Simulation Software

\section{Introduction}

"Digital circuit" belongs to the main course of electronic information specialized course (Mutoh et al., 1995), which has the characteristics of strong engineering practice, fast updating of course content and rapid development of frontier research (Boyd et al., 2005). Because of this, it is imperative to reform the teaching of "digital circuit" course, improve the teaching methods and practice the teaching strategies (Vassilev \& Miller, 2000). Based on the current development of digital circuit technology, some suggestions are put forward from the aspects of guiding ideology, teaching content, and teaching methods (Jutman et al., 2002). Among them, the article points out that the design method and the new tech- 
nology supplement are the key points of the teaching content reform (Liu, 2014). The teaching content should increase the practice teaching. The teaching method should focus on the increase of teaching content, make use of classroom discussion, and enhance students' subjective initiative and self-learning ability (Peng, 2010). At the same time, we should improve the examination methods and increase the experimental examination (Lai \& Hwang, 2016; Lu et al., 2017). In terms of teaching methods, multimedia, computer simulation and network teaching are mentioned to enhance the teaching effect (GebreYohannes et al., 2016). This paper summarizes the teaching method of digital circuit and provides some guidance and reference for the teaching method practice of digital circuit and relevant information.

In 2020, due to COVID-19, more than 190 countries around the world have suspended classes, affecting more than 1.7 billion students (Zhou et al., 2020). How to carry out online education effectively has become a common concern for both teachers and students during school closures (Leung et al., 2020). In the face of the epidemic, the Ministry of Education of China attaches great importance to education and teaching under the epidemic situation (WHO, 2020). In view of the characteristics of online education, it has issued a series of guiding opinions and countermeasures, and implemented the education policy of suspending classes without ceasing classes (Jaggars \& Xu, 2016). Digital circuit is a course that involves both theoretical learning and experiment. Online education is facing greater challenges. The following will introduce the design of digital circuit online course in this semester, analyze the problems in the process of teaching, think about how to impart knowledge and skills more effectively in the network environment, summarize the experience of online teaching, and comprehensively reflect and improve the teaching intention, teaching design, teaching behavior and their relations.

The problem of this research is how to increase practical teaching in teaching and how to apply theory in teaching methods. The objective of this paper is to enhance the students' subjective initiative and self-learning ability through classroom discussion, and to improve the examination methods and increase the experimental assessment. In terms of teaching methods, it is mentioned that multimedia, computer simulation and network teaching should be used to enhance teaching effect. This paper summarizes the teaching methods of digital circuit and provides some guidance and reference for the teaching methods practice of digital circuit and relevant information.

\section{Digital Circuit Online Course}

\subsection{Online Course Design}

"Digital circuit" is one of the important professional basic course of electrical engineering, is the study of digital system design of an introductory course, aims to lead the students to master the basic theory of digital logic circuit and basic circuit analysis and design methods, to engage in conventional logic circuit de- 
sign, for learning the follow-up courses to prepare necessary knowledge of circuit and the design method (Wang, 2016). It is a course with strong theory and practice. The mathematical theory is based on Boolean algebra, which involves the basic axioms, theorems and rules of logical algebra. There are a lot of logic circuit design, logic reasoning and logic operation in the teaching process. The four parts from the elementary to the profound, are shown in Figure 1.

The traditional classroom teaching concept is knowledge-centered. At the level of teaching, the classroom is basically based on teachers' combined teaching materials, which makes students inevitably feel abstract, boring and difficult to understand in the learning process. It is difficult to combine abstract knowledge with practical application. Due to the epidemic, the course learning of "digital circuit" needs to be conducted online. Our teaching team communicated and discussed through the online meeting, designed the teaching content, and did the following work. The core of "heuristic" teaching concept lies in "asking questions", that is, constructing dialogue situation based on question exploration, advocating the use of questioning and rhetorical questions to subtly transform the learning content into teaching dialogue centered on question exploration. Thus stimulate students' learning motivation and help students understand. Based on the popularity of "digital circuit" course and students' different degrees of knowledge mastery, it is proposed to adopt the heuristic teaching mode summarized by "digital circuit" course in the past 30 years. The "heuristic" teaching mode mainly includes four aspects: "asking questions", "enlightening thinking", "dichotomous solutions" and "comparative analysis".

\subsection{Prepare Preview Materials}

In order to change the traditional teaching mode filled by teachers, we screen out network quality resources before each class, and reintegrate them according to our own situation. We make preview courseware and push it to students through the rain classroom platform, to fully stimulate the brain potential of students, and achieve the aim of drawing cocoons, removing silk and abstracting the main picture. Through preview, students can understand the important and difficult points, learn independently with guidance, and grasp the whole picture of "digital circuit" course. Then, through teacher's explanation, students can strengthen their understanding of knowledge, which is beneficial to the cultivation of students' thinking quality. Our teachers guide their own teaching by making or viewing the preview courseware, so that the teaching objective is more clear and the teaching method is more scientific, which is conducive to improving the teaching effect.

"Asking questions" is the first step of heuristic teaching, which is mainly designed for the introduction of concepts and methods in "digital circuit" course. In general, "asking questions" is aimed at a concept that has not been learned. At this time, "asking questions" has also become the core content of background extension teaching method. By "asking questions", new concepts are introduced, 


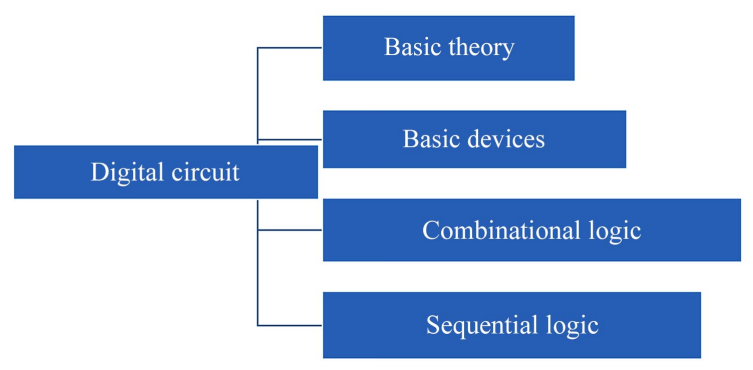

Figure 1. Four parts of digital circuit.

which can greatly stimulate students' learning motivation. The specific practice process of "raising questions" is as follows: when the teacher explains each part of the content, he will introduce it by way of example, and let the students think about what is the background of this concept or method? Thus further leads to the concept in the digital system how to tell the status. It is very important to apply "heuristic teaching" to put forward the corresponding questions according to the teaching content and guide the students to think alternately. As mentioned above, the core of "heuristic" teaching concept lies in "asking questions", that is, it is extremely critical to disassemble and develop various problems according to the teaching content. In the teaching practice link, "disassembling questions" and subsequent "enlightening thinking" strategies are specifically adopted. In the specific teaching practice, "enlightening thinking" is often accompanied by "alternating thinking" and "progressive layer by layer", which enlighten and decompose the questions raised little by little. For example, when teaching encoders, the application example is: Ask the student how to transmit the information typed on the keyboard to the computer; Is it transmission in what form?

\subsection{Explain in Combination with Practical Application}

After providing students to preview the courseware, students can study autonomously with guides, while classroom teaching is still necessary. The course of "digital circuit" has complex levels and open problems. If it is not connected with the actual situation, students will feel that the knowledge and concepts are endless and cannot learn the right way. Combined with the practical application of digital circuit, the knowledge points taught in class can make up for the lack of abstract and boring teaching content.

The classroom teaching process is case-driven and consolidates what is taught. From basic gate circuit to combinational logic circuit, to sequential logic circuit and the generation and shaping circuit of pulse waveform, etc., we found and summarized some cases from the perspective of life and science popularization, which can be easily introduced in class.

\subsection{Teaching Design and Practice}

This semester, the online course "digital circuit" adopts the mode of combining 
rain classroom and Tencent classroom. Because different platforms have their own characteristics, they are used in different ways. Preview videos, homework and irregular classroom tests are pushed through the rain class. Online live courses are taught through Tencent classroom, and knowledge requirements, online tests, discussions and questionnaires we have designed in advance are completed. This teaching method divides the teaching process into pre-class preparation, classroom learning and after-class consolidation and expansion.

In the course of classroom learning, according to the characteristics of the learning content, in addition to the part explained by the teacher, flipped it appropriately, including group discussion, student explanation, experimental operation, etc. We set up a curriculum questionnaire in each homework. The teacher can see and give feedback when the students put forward their unclear points. At the same time, the automatic recording function of Tencent classroom enables students to watch teaching videos repeatedly or fast forward after class, effectively solving the problem of absence from class and uneven student foundation caused by special circumstances. In the teaching process, a systematic mixed teaching process is constructed with the content of each chapter of the textbook as the surface, the preview requirements as the line, the knowledge points as the teaching focus, and the students as the leading role. Some cases of digital circuit are shown in Table 1.

\subsection{Experimental Design}

Theory of digital circuit experiment teaching, including course involved in important knowledge, a basis for the verification experiments, comprehensive experiments and designing experiments, the main purpose is to make students master the basic method of digital circuit measurement, debugging, and cultivate students' comprehensive ability to use learning theory to complete the digital circuit design. Through the experiment, firstly, students can deepen the understanding of the basic working principle and basic analysis method of digital circuit. Second, it can be operated independently. The teaching mode is shown in Figure 2.

In gerneral, due to the epidemic, all experiments in this semester can only be carried out online. So the use of software is very important. We chose Multisim simulation software to conduct online experiments. Multisim is an EDA tool for electronic circuit simulation and design launched by National Instrument NI Company. It has a rich component library and virtual test instruments, intuitive operation interface and complete analysis means. The Multisim simulation software is flexible, which can not only analyze and test the circuit, but also modify the experimental circuit conveniently, is an effective supplement to experimental teaching. Through the simulation software, students can build their own circuit, verify the experimental results, abstract into concrete, improve the ability of independent learning. With the application of Multisim simulation software, students are required to make clear the experimental requirements, 


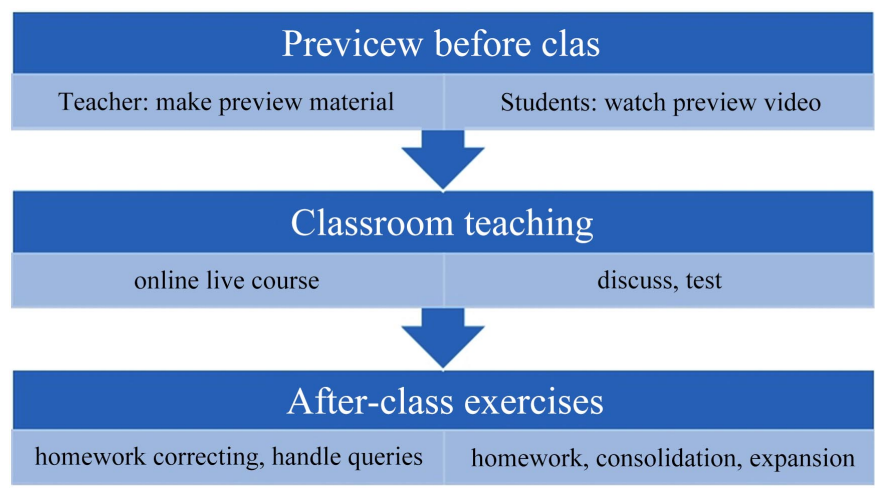

Figure 2. Teaching model.

Table 1. Digital circuit cases.

\begin{tabular}{cc}
\hline Case & Knowledge used \\
\hline Three persons responder circuit & Sequential logic \\
Vending machine & Sequential logic \\
Sequence signal generator & Sequential logic \\
Water level monitoring circuit & Combinational logic \\
Traffic light circuit & Combinational logic, Sequential logic \\
\hline
\end{tabular}

understand the use methods of relevant instruments and devices, and design circuits or schemes before the experiment. During the experiment, the schematic diagram was drawn on Multisim platform for simulation verification and experimental results were analyzed. The combination of simulation experiment and theoretical learning deepens and expands students' understanding of digital circuit theory.

\subsection{Research Method}

"Problem dismantling strategy" is to break down "big problems" into "small problems" and then solve them one by one. For example, when teaching encoders, it is important for students to be able to design encoders. In other words, "designing a coder" is a "big problem". Circling around this "big problem", how to condense out a series of "small problems", and then guide students to solve step by step, is the main content of heuristic classroom teaching design. Centering on the "big problem" of how to use Multisim simulation software, we condensed the following "small problems": 1) Starting with the keyboard that students are familiar with, we raised a question: Is there any code in the keyboard? 2) Based on computer keyboard, including mobile phone keyboard and input keyboard, let students think about how to code? 3) Are there any other coding methods in our life?

After the "big problem-small problem" is given, the students are guided to "alternate thinking" to make them have perceptual thinking and deep impression on the content to be taught, that is, the following series of "alternate think- 
ing" questions are adopted: 4) How to conduct simulation experiment of Multisim? 5) What should the simulation experiment look like? 6) How many inputs and outputs should the code have? 7) What should its logical diagram be? 8) How to design the gate circuit? In the above Questions 4) to 8), a certain amount of time is set aside for students to think about each question. In the process of students' thinking, opposite, incomplete or biased answers are given. After observing students' reactions, correct answers are given.

\section{The Teaching Feedback}

Online teaching brings convenience in some aspects, such as the function of automatically correcting objective questions in the rain classroom, which reduces the workload. The recording and broadcasting function of Tencent classroom reduces the number of repeated lectures. But this model also puts higher demands on us. The modern teaching platform is just a convenient tool. It is up to the users to make the most of it. Teachers should constantly improve themselves. Through the questionnaire survey, we know the students' opinions are as follows. The advantages of online courses are: 1) not limited by time and space, convenient and efficient; 2) can repeatedly learn, make up the gap; 3) at least the general time no class, free to control. But there are also some students have the opposite opinion: lack of effective study supervision. Lack of learning interaction, oneself cannot feel the learning atmosphere, learning effect is not good; the online course materials are too heavy, and the preview link is increased at the same time, which causes heavy study and affects the learning efficiency.

According to students' feedback on online teaching, with the help of modern Internet technology, teachers can't teach face-to-face like traditional classes, but they also have many advantages. For example, a teacher's lecture video can be played back through the network, students can listen to it again and again if they do not understand it once, and students can listen to it alone without being disturbed by other factors. Students can live and sleep at home, which avoids travelling back and forth on the way to school and saves a lot of time. For homework, students take photos and send them to the teacher after they finish the homework, or submit the homework directly after they finish it online. Teachers have a better understanding of whether students have completed their homework or not, and there is no difference in the quality of homework in classroom teaching.

\section{Improvements of Online Course}

Based on the students' feedback and the above questions, we have considered and made improvements from the following aspects:

1) Strengthen supervision

While higher education gives students more freedom to learn, online classes require more discipline than offline ones. Because teachers and students cannot face each other, it is difficult for teachers to monitor students' concentration in 
real time. In terms of teaching supervision, there is still a gap between online education and offline classroom discipline supervision, and the realization of teaching objectives becomes more difficult.

In order to ensure the learning effect of students, teachers can guide students to study seriously through technical means. Interactive links can be added in the class, and the functions of raising hands and streaking in the live class can achieve the same effect of asking questions offline. Before and after class, it is convenient to check students' preview and homework, provide feedback to students in time, and urge them to study in time.

2) Build study groups to increase interaction

Traditional offline teaching is limited by classroom discipline, so students will be more restrained in the classroom and have insufficient motivation to interact with teachers in class. While through the Internet, students have more freedom, and teachers should encourage students to communicate with teachers in different ways. They can not only communicate in class groups, but also interact with each other in class through voice, bullet screen and other ways close to the characteristics of young people.

At the same time, by grouping students, a similar offline atmosphere of colearning is provided, so that students can participate in relatively free learning discussions and improve learning efficiency. At the same time, let the students show their learning results through group activities, which can help them keep the exuberant motivation of learning.

3) Integrate resources and adjust goals

With so many online teaching resources, it can provide students with more choices, but it also puts a burden on students. Therefore, teachers need to help students understand the learning objectives, targeted learning. Studies have found that learning something relatively straightforward keeps students interested and increases student engagement. This requires that teaching objectives should not be set too high. In the course of learning, we should clearly point out to students the degree of learning a certain topic, so as to achieve a targeted goal. In the long run, it can stimulate students' enthusiasm instead of just studying for exams.

\section{Summary and Conclusion}

This paper introduces the design and experience of network course. In the construction of digital circuit course of network course, network classroom teaching mode should be adopted to improve the teaching quality. We constantly strive to explore in practice, and constantly sum up experience, for a more suitable for the effective teaching pattern of "digital circuit", and we also have been in reflection about how to give full play to the advantages of this teaching mode, and so truly.

In general, the goal of "learning-centered" teaching reform is to cultivate students' self-learning ability and improve the quality of talent cultivation. Teachers 
should improve their sense of responsibility, innovate their teaching and learning modes according to students' cognitive rules and accepting characteristics, and teach according to their abilities. Through constant reform, they can achieve the goal of cultivating students' knowledge, ability and quality. At the same time, students complete the task of learning, to make it become a high-quality talent to lay a good foundation.

\section{Acknowledgements}

This work was funded by collaboration between industry and school Project of Ministry of Education: "Innovative teaching and training of PAEE system in electronic information major" (No. 201901103032).

\section{Conflicts of Interest}

The author declares no conflicts of interest regarding the publication of this paper.

\section{References}

Boyd, S. P., Kim, S.-J., Patil, D. D., \& Horowitz, M. A. (2005). Horowitz MA. Digital Circuit Optimization via Geometric Programming. Operations Research, 53, 899-932. https://doi.org/10.1287/opre.1050.0254

GebreYohannes, H. M., Bhatti, A. H., \& Hasan, R. (2016). Impact of Multimedia in Teaching Mathematics. International Journal of Mathematics Trends and Technology, 39, 80-83. https://doi.org/10.14445/22315373/IJMTT-V39P510

Jaggars, S. S., \& Xu, D. (2016). How Do Online Course Design Features Influence Student Performance? Computers \& Education, 95, 270-284.

https://doi.org/10.1016/j.compedu.2016.01.014

Jutman, A., Ubar, R., Hahanov, V., \& Skvortsova, O. (2002). Practical Works for On-Line Teaching Design and Test of Digital Circuits. 9th International Conference on Electronics, Circuits and Systems, Dubrovnik, 15-18 September 2002, 1223-1226. https://doi.org/10.1109/ICECS.2002.1046474

Lai, C.-L., \& Hwang, G.-J. (2016). A Self-Regulated Flipped Classroom Approach to Improving Students' Learning Performance in a Mathematics Course. Computers \& Education, 100, 126-140. https://doi.org/10.1016/j.compedu.2016.05.006

Leung, C. C., Lam, T. H., \& Cheng, K. K. (2020). Mass Masking in the COVID-19 Epidemic: People Need Guidance. The Lancet, 395, 945. https://doi.org/10.1016/S0140-6736(20)30520-1

Liu, Q.-X. (2014). Experiment Teaching of Digital Electronic Technology Using Multisim 12.0. World Transactions on Engineering and Technology Education, 12, 37-42.

Lu, O. H., Huang, J. C., Huang, A. Y., \& Yang, S. J. (2017). Applying Learning Analytics for Improving Students Engagement and Learning Outcomes in an MOOCs Enabled Collaborative Programming Course. Interactive Learning Environments, 25, 220-234. https://doi.org/10.1080/10494820.2016.1278391

Mutoh, S., Douseki, T., Matsuya, Y., Aoki, T., Shigematsu, S., \& Yamada, J. (1995). 1-V Power Supply High-Speed Digital Circuit Technology with Multithreshold-Voltage CMOS. IEEE Journal of Solid-State Circuits, 30, 847-854. https://doi.org/10.1109/4.400426

Peng, W. (2010). Practice and Experience in the Application of Problem-Based Learning 
in Computer Programming Course. In 2010 International Conference on Educational and Information Technology (pp. V1-170-V1-172).

https://doi.org/10.1109/ICEIT.2010.5607778

Vassilev, V. K., \& Miller, J. (2000). Scalability Problems of Digital Circuit Evolution Evolvability and Efficient Designs. In Proceedings of the 2nd NASA/DoD Workshop on Evolvable Hardware (pp. 55-64).

https://doi.org/10.1109/EH.2000.869342

Wang, J. (2016). Analysis and Exploration on” Digital Circuit” Course Teaching Reform of the Vocational Colleges. In 4th International Conference on Management Science, Education Technology, Arts, Social Science and Economics 2016 (pp. 33-36). https://doi.org/10.2991/msetasse-16.2016.9

WHO (2020). Coronavirus Disease 2019 (COVID-19): Situation Report (p. 88).

Zhou, T., Huang, S., Cheng, J., \& Xiao, Y. (2020). The Distance Teaching Practice of Combined Mode of Massive Open Online Course Micro-Video for Interns in Emergency Department during the COVID-19 Epidemic Period. Telemedicine and e-Health, 26, 584-588. https://doi.org/10.1089/tmj.2020.0079 